\title{
Voting Advice Applications under review: the state of research
}

\section{Diego Garzia*}

European University Institute,

Via delle Palazzine 17,

I-50014 San Domenico di Fiesole, Italy

Email: Diego.Garzia@eui.eu

*Corresponding author

\section{Stefan Marschall}

Heinrich-Heine-Universität Düsseldorf,

Universitätsstraße 1,

D-40225 Düsseldorf, Germany

Email: stefan.marschall@uni-duesseldorf.de

\begin{abstract}
In recent years, Voting Advice Applications (VAAs) have become a relevant object of political science research. The aim of this paper is to develop a map of the existing literature and to outline a research agenda for this increasingly relevant tool and its role within modern democracies. Starting point of the paper is the dissemination of VAAs in Europe, focusing on the differences and similarities between the main types of VAAs. After having outlined the reasons for the dramatic spread of VAAs among European countries and voters, we provide an overview on the existing VAA literature. We then present a comparative research agenda for the VAAs by identifying questions that could be posed to the tools and their role out of different analytical perspectives. In the conclusion, we bring forward the argument that VAAs might matter even more in the future, indicating the need for a coordinated research effort.
\end{abstract}

Keywords: e-democracy; internet; issue voting; political communication; turnout; voting behaviour.

Reference to this paper should be made as follows: Garzia, D. and Marschall, S. (2012) 'Voting Advice Applications under review: the state of research', Int. J. Electronic Governance, Vol. 5, Nos. 3/4, pp.203-222.

Biographical notes: Diego Garzia is Jean Monnet post-doctoral fellow at the European University Institute, Florence. The long-term focus of his research focuses on the drivers of voters' choice in Western Europe. His current research project investigates the potential of Voting Advice Applications to affect voters' behaviour in both quantitative and qualitative terms. He authored numerous academic publications including articles in Party Politics, Political Psychology, Political Research Quarterly and The Leadership Quarterly. In 2010, he co-edited Voting Advice Applications in Europe: The State of the Art - the first comparative volume ever devoted to VAAs and their effect on users' electoral behaviour. 
Stefan Marschall is a full Professor of political science and Chair of German Politics at the Department of Social Sciences of Heinrich-Heine University Düsseldorf/Germany. He is a specialist on the political system of Germany, political (online) communication and comparative as well as transnational parliamentarism. He has published text books on the political system of Germany and on parliamentarism as well as numerous journal articles and book chapters on political (online) communication and parliamentary affairs. He is in charge of the research on the German Voting Advice Application "Wahl-OMat" since 2003.

\section{Introduction}

Within the last two decades, the internet has emerged as a widely used platform supplementing traditional media such as television, radio and newspapers, as well as playing a vital role within the realm of political communication on different levels of social stratification (Chadwick and Howard, 2009). On the meso-level of organisations, corporative political actors such as parties, interest groups and government bodies use internet communication to organise their members or to communicate directly with their target groups. On the micro-level of the individual citizens, for many persons political online communication has turned into a major - and for some the only - source of political information, communication and participation (Zittel and Fuchs, 2007; Norris, 2008). Research has generated considerable evidence that in Western democracies the emergence of the internet resulted in a significant change within political behaviour, especially in voting behaviour (Wagner and Gainous, 2009; Leighley, 2010). Indeed, a lot of attention has been given to the role of the internet before election times (Kluver et al., 2007). New forms of campaigning have been established: candidates and parties use web applications to present themselves and their policy positions, to collect donations for their campaigns, to rally around their supporters and to recruit new "friends" and members (Gibson et al., 2003).

Not only parties and candidates but also non-party organisations offer online applications prior to elections (Farrell and Schmitt-Beck, 2008). This paper will focus on one type of a non-party online tool that has mushroomed within the last years in European countries and beyond: Voting Advice Applications (hereafter: VAAs). ${ }^{1}$ The increasing popularity of these tools is closely related to the progressive erosion of traditional anchors of voting behaviour in democracies (Franklin et al., 1992; Dalton and Wattenberg, 2000) and to the corresponding emergence of new tendencies such as issue voting (Dalton, 2002; Aardal and van Wijnen, 2005). Issue voting is based on the assumption that voters' choices are determined by their proximity or distance to the positions of the parties on salient political issues. In order to link their policy preferences to the parties' positions, voters need not only to have developed a preference, but also should have gathered a sufficient amount of information about the policy stands of each competing party (Downs, 1957; Carmines and Huckfeldt, 1996). This is where VAAs come into the picture.

Although different in some respects, Voting Advice Applications share a common operating principle: They compare the positions of parties (or candidates) on a selection of policy issues with the position of the voter; at the end they calculate and display a rank-order list, at the top of which stands the party closest to the voter within the 
$n$-dimensional issue space (Edwards, 1998). By linking the voter's position on the various policies with that of the parties, VAAs represent a potentially useful compass for the rising number of issue voters in contemporary democracies (Garzia, 2010).

In some countries, VAAs like the "Stemwijzer" (Netherlands) or the "Wahl-O-Mat" (Germany) have developed into outstandingly popular political web applications used by a remarkable share of voters - e.g. the "Stemwijzer" was used more than 4.9 million times by the Dutch electorate in 2012; the "Wahl-O-Mat" was used 6.7 Million times at the national elections 2009 (see de Graaf, 2010; Marschall and Schmidt, 2010). As VAAs have been established in many countries and as they have been used intensively by the respective electorates, they have started to constitute a relevant field of social science research. In the last years, workshops, conferences and research projects have been conducted on different VAAs resulting in a still relatively small body of VAA research literature Section 4). This paper tries to develop a map of the existing but as yet unconnected VAA studies and to outline a research agenda for this increasingly relevant tool and its role within modern democracies.

The starting point of the paper is the dissemination of Voting Advice Applications in Europe. Section 2 presents the results of a survey on the diffusion of these tools among European countries, focusing on the differences and similarities between the main types of VAAs. In Section 3 we set forth a number of reasons (at both macro- and micro-level) for the dramatic spread of VAAs among European countries and voters. Having outlined the empirical basis of the phenomenon, Section 4 provides an overview of the existing VAA research, primarily concentrating on the tool's impact on political behaviour. As there is no coordinated VAA research programme so far, we try to identify common underlying patterns of the existing research in terms of their methodological design as well as in terms of their findings. Section 5 presents a comparative VAA research agenda by identifying questions which could be posed to the tool and its role out of different analytical perspectives (e.g. political behaviour, party research, political communication, democratic theory). In the end we put forward the argument that considering changes in political communication and in voting behaviour, VAAs might play an even more decisive role in the future, indicating the need for a coordinated research effort on Voting Advice Applications.

\section{Differences and similarities within the group of VAAs}

Over the last years, Voting Advice Applications have mushroomed in Europe and beyond (e.g. Marzuca et al., 2011). To acquire an overview on the dissemination of these tools, we conducted a survey drawing on the analysis of literature and a web-based data collection. Focusing on VAA versions that have been developed on the national level (i.e. VAAs applied for national or European elections, as well as transnational versions for the elections of the European Parliament), over 40 online tools of this kind have been implemented in Europe within the last years. We found at least one operating VAA in all but two EU countries (Malta and Slovenia); in some nations, more than one VAA has been launched.

Except for a few cases, nearly all of the tools have been established after 2000. One of the exceptions is the Dutch "Stemwijzer", which was produced for the first time in the mid-1990s as an online application - after it had been offered in paper-and-pencil form already in the 1980s (de Graaf and Schuszler, 2005; de Graaf, 2010). A VAA had been established in Finland as well as early as in 1996 (Ruusuvirta, 2010). Apart from these exceptions, the effective spread of VAAs started in the late 2000s. 
Table 1 Voting Advice Applications in Europe (selection)

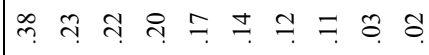

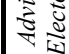

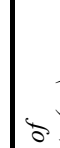

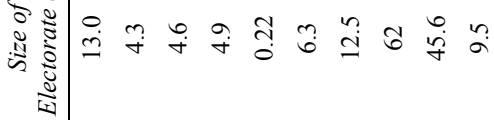

象

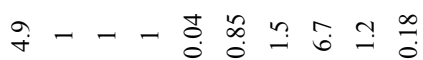

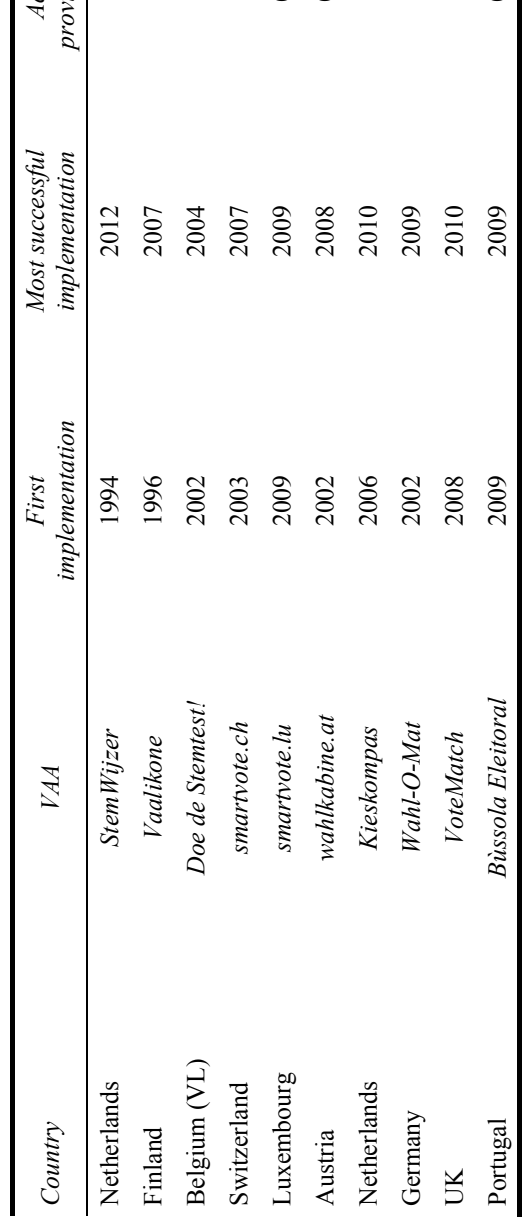


Table 1 presents information on the dissemination of a selection of Voting Advice Applications in Europe, restricted to the ten most frequently used applications (taking into account the proportion of advices provided by each application in a given election as compared to the national electorate's size) among those surveyed. ${ }^{2}$ As far as data was provided by the organisations offering VAAs, the Dutch "Stemwijzer" in the national elections of 2012 can be considered the most successful implementation of a VAA so far which taken by the numbers of its usages might have reached $38 \%$ of the electorate. In absolute numbers, the German "Wahl-O-Mat" launched before the national elections in 2009 scored the largest number of advices ever: 6.7 million.

VAAs have not only been deployed for national elections. Before the European election of 2004, an "EU-Votematch" was launched that calculated the distances between the voters and the transnational party groups of the European Parliament. Five years later, before the European elections of 2009, two supranational VAAs could be used by the European voters. For the second time an "EU-Votematch" version was offered. Additionally, the transnational VAA "EU Profiler" was produced by the European University Institute in Florence, offering national versions on a common platform which added to specific national policy issues a set of shared European ones (Breuer, 2010; Trechsel and Mair, 2011).

Although sharing the same basic operating principle, i.e. to compare the positions of voters' with positions of parties/candidates and at the end indicating the summed proximity, VAAs differ in several aspects from each other, and in particular with respect to:

- the organisation that is in charge of the tool: Different types of organisations provide Voting Advice Applications to the voters ranging from private entrepreneurs such as single persons (French "Mon Vote À Moi") or media companies (Finnish "Vaalikone"), via NGOs (British "VoteMatch") and universities ("EU Profiler") to government-linked agencies (German "Wahl-O-Mat"). Some VAAs are produced and offered as a result of cooperation between different types of organisations (e.g. Swedish "Aftonbladets Valkompas" which is the product of collaboration between a university and a media company). The respective organisational background correlates with varying financial resources the providers of VAA can draw on.

- the range of parties whose positions are considered in the VAA: Generally taken, a broad and a narrow approach to the selection of candidates and parties can be distinguished. Tools like the Dutch "StemWijzer" or the German "Wahl-O-Mat" encompass all candidates or parties that compete against each other, whereas VAAs like the Belgian "Doe de Stemtest!" take into account only a selection of parties with whose positions the voter can compare himself/herself. If the "narrow approach" is applied, a dominant criterion for the selection is whether parties already have seats in parliament. The need for a selection depends strongly on the fragmentation of the respective party system and the total number of parties taking part in an election.

- the quantity and quality of the propositions: The policy propositions or "theses" are at the heart of Voting Advice Applications. However, the tools differ concerning the number of propositions they confront users with; comparably long lists of policy questions encompass about 45 to 50 propositions (Swedish "Valpejl"), as compared to short lists of only about 9 topics (Czech "Volební rádce"). Tools like the Swiss "smartvote" leave it to the choice of the users as to whether they prefer to respond to 
a small or large number of propositions. Also, VAAs differ in terms of the quality of the theses: whether they address concrete policy issues only (German "Wahl-OMat") or whether they inquire more general political attitudes (Irish "Pick Your Party").

- the way the propositions are developed: With some VAAs the production of propositions is solely generated by experts such as journalists and political scientists who draw on party platforms provided prior to the elections (Austrian "wahlkabine.at"); some of the tools include the participation of party actors in the production of the VAA theses, for example by inviting party representatives to workshops (Dutch "StemWijzer"). Additionally to professional experts, in the German "Wahl-O-Mat" first and second-time voters play a crucial role as members of an editorial board that is in charge of formulating the propositions.

- the identification of the parties' positions: Broadly speaking, three methods of identifying policy positions of the parties are applied. Firstly, the issue positions are established independently from the parties, for instance through surveys of country experts (Italian "ITANES VoteMatch"); secondly, the parties are asked to position themselves along the propositions, but their responses might be subject to corrections by experts (Dutch "Kieskompas"); thirdly, the parties are invited to vote on the theses authoritatively without being subject to changes by the tool's providers (German "Wahl-O-Mat").

- the answer pattern: VAAs provide the users different scales to express their positions on the theses. A majority of the tools offer simply three response options (e.g. "agree"/"yes", "disagree"/"no", "undecided"/"neutral"); in some of the tools this scale is supplemented by the option "skip proposition". Other VAAs offer five answer options (e.g. Likert-scale ranging from "strongly agree" to "strongly disagree") or ask the users to take position on a continuum (Irish "Pick Your Party").

- weighting of propositions: Nearly all VAAs allow to attach weight to those theses which are of special salience for the individual voter; in some VAAs the weighting is even compulsory if the user wants to proceed (Romanian “Testează-ți Votul!"). If weighting is offered, it can be done for all propositions after the user has voted on the theses (German "Wahl-O-Mat") or for each proposition separately while the voter responds to the single issues (Lithuanian "Mano Balsas"). Weight can be laid on single propositions one by one - as in most of the VAAs that allow for weighting - or on groups of positions (Irish "Pick Your Party"). For the weighting of theses, different scales ranging from dichotomy to a nine-step scale like in the Austrian "wahlkabine.at" are applied.

- the calculation method: Different methods are used to compute the proximity of the voters' position to the stances of the parties or candidates, inter alia depending on the answer scales applied (for a review, see: Louwerse and Rosema, 2011). One approach calculates "congruousness" between users' and parties' positions by summing up in how many cases the two answer patterns match (Finish "Vaalikone"). Yet the predominant way is the measurement of distances between the answer patterns of the parties and those of the users, for example by using the City Block method (Dutch "StemWijzer" or German "Wahl-O-Mat"). This calculation method is displayed in Table 2. 
- the illustration of proximity/distance: The final result of the calculation, i.e. the summed proximities or distances between the users and the parties/candidates, might be displayed in different ways. One frequently used "Stemwijzer" type variant is a one-dimensional ranking list starting on the top indicating the party with the highest proximity and ending with the party which is most distant to the voter (e.g. German "Wahl-O-Mat"; see Figure 1). Alternatively, the relationship between party and voter is depicted in a more complex graphic illustrating proximity or distance on different policy dimensions (e.g. in form of a Smartspider like in the "EU Profiler"; see Figure 2).

Table 2 Scoring on the basis of closest distance

\begin{tabular}{lccc}
\hline Voter: & Parties: & Neutral & Agree \\
\hline Disagree & 0 & 1 & 2 \\
Neutral & 1 & 0 & 1 \\
Agree & 2 & 1 & 0 \\
\hline
\end{tabular}

Source: de Graaf (2010)

Figure 1 One-dimensional ranking list (see online version for colours)

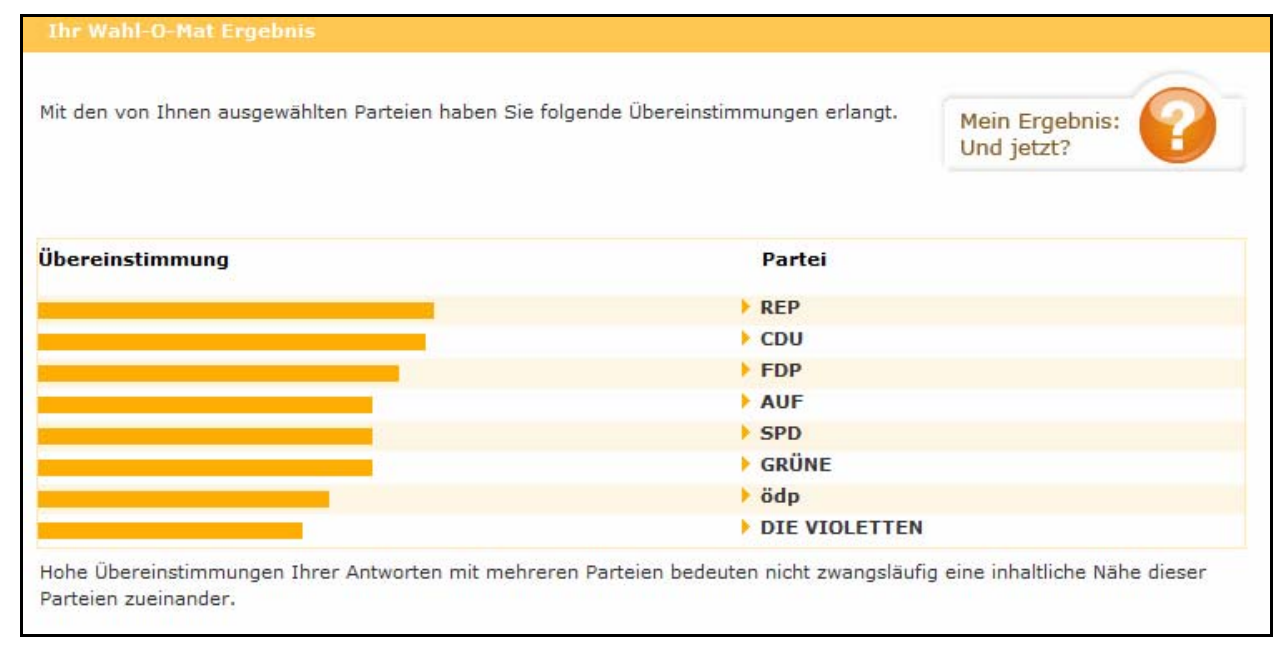

Source: http://www.wahl-o-mat.de

Apart from these differences, some supplementary characteristics beyond the basic definition mentioned in the introduction emerge as being typical for Voting Advice Applications. Firstly, the tools are generated by "non-party" organisations, many of them with a civic education background. As such, they claim for themselves to be neutral with respect to specific parties and/or candidates in an election. Regarding their content, the great majority of VAAs is prospective and issue-oriented as they focus on policy pledges within election campaigns leaving aside retrospective performance evaluations as well as candidates' personality assessments. 
Figure 2 The "Smartspider" (see online version for colours)

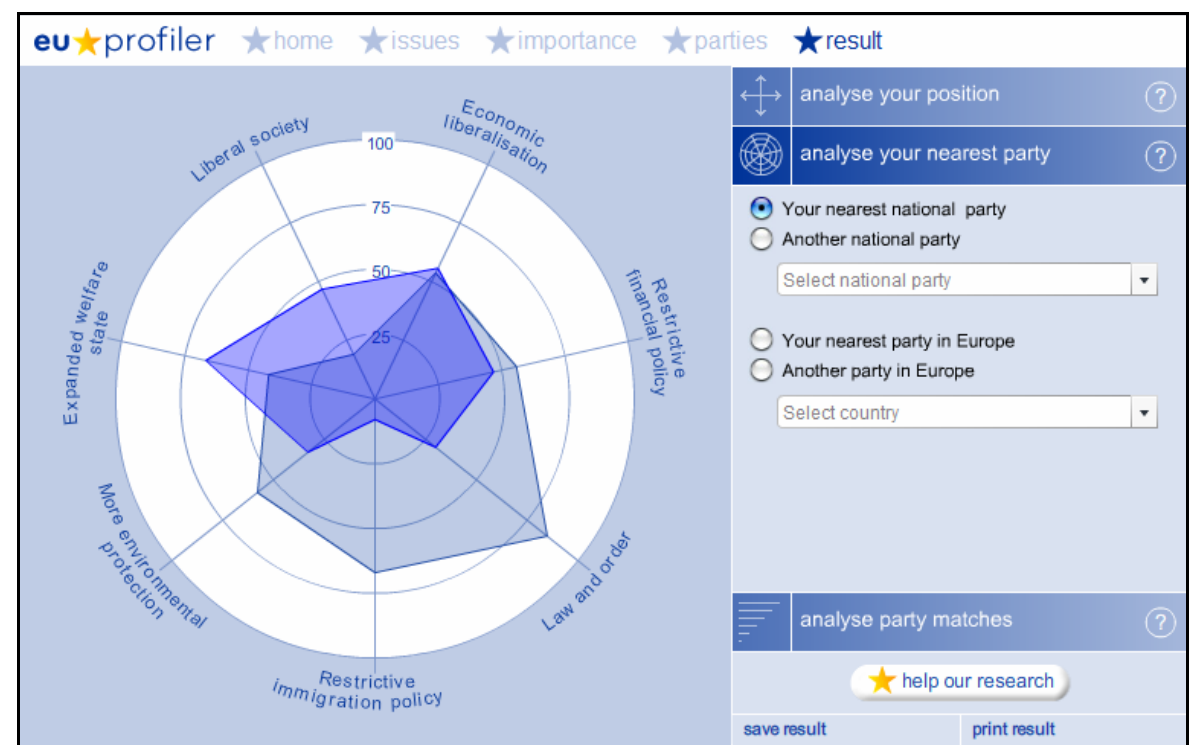

Source: http://www.euprofiler.eu

\section{The success of VAAs: explaining factors}

The widespread and rapid diffusion of this type of tool is obviously linked to the rise of the internet (Hooghe and Teepe, 2007). On the one hand, technological developments made the production of VAAs easier; on the other hand, the pervasive diffusion of the medium rendered them easily accessible to a huge number of potential users. However, the internet alone cannot possibly account for the success of VAAs.

One plausible and empirically based explanation builds on a "snow-balling" or "shopping" model: Once such a tool has become successful in a country and this phenomenon is then observed by or communicated to actors such as media or organisations of civic education in other countries, these actors have imported the idea into their own national contexts. Certain channels promoted the spread of VAAs, e.g. the Network of European Citizenship Education (NECE) - a group that encompasses agencies and NGOs in the field of citizenship education from 25 European countries, serving as a forum for the presentation of VAA projects. ${ }^{4}$ The production of the "EU Profiler" for 27 countries relying on the support of local expert teams also served as a channel of dissemination of the VAA idea to other European countries.

To explain the growing popularity of VAAs within European electorates, a number of context-specific conditions should also be taken into account. In relative terms (that is, the proportion of advices provided by the various applications compared to the national electorate's size) the VAA phenomenon is more established in The Netherlands, Belgium, and Finland (see Table 1). These are the three countries in which VAAs have appeared first allowing the electorate at large to become familiar with these applications over the years. The way in which traditional mass media promotes these applications is 
also a key to understanding the popularity of VAAs (Ruusuvirta, 2010). Indeed, the very same countries are also those in which VAAs have been the protagonist of a national TV show (Walgrave et al., 2008).

Moving to polity specific aspects, the structural conditions under which voting takes place represent a crucial factor of explanation for the spread of VAAs. The electoral system employed seems to make a difference: Enhancing the chances for the representation of a greater number of parties, proportional representation (PR) systems offer a fertile ground for this kind of tools. Indeed, apart from the British "Vote Match", all the strongly used VAAs reported in Table 1 have been developed within PR countries. Also the openness of the ballot structure could matter: By allowing voters to express multiple candidate preferences, open list systems foster in turn the usage of candidatecentred VAAs in countries such as Finland and Switzerland (Ruusuvirta, 2010).

As a related factor, the erosion of cleavage-based voting (Franklin et al., 1992) and partisan alignments (Dalton and Wattenberg, 2000) in Western democracies might have augmented the number of floating, undecided voters who resort to VAAs in order to find orientation for their voting decision (Dalton et al., 2000). Aggregate-level data suggest that in those countries where electoral volatility is higher (cf. Scarrow, 2010), VAAs are used the most. These first and prima facie observations call for more systematic research to understand the range of success of VAAs within diverse national settings as well as the interrelationship between the potential explanatory factors discussed so far.

\section{The state of the art in VAA research: approaches and findings}

Despite the impressive number of users resorting to VAAs throughout Europe, academic research in the field is still rather scant and disconnected. In the early phase of VAArelated research, involved scientists attempted by and large to establish a common language for future studies (Fivaz et al., 2010). Indeed, a common agreement that these tools constitute a coherent group of applications and how this group should be called was reached only recently. In more recent years, a new stream of quantitative research on VAAs has emerged. A (still small) number of papers dealing with VAA effects and methodology have appeared in highly ranked political science journals (e.g. Walgrave et al., 2008; Walgrave et al., 2009; Wagner and Ruusuvirta, 2011; Wall et al., 2012) and in the first comparative volume ever devoted to the subject by Cedroni and Garzia (2010).

Different perspectives have been employed in the scientific analysis of VAAs. Early studies have primarily concentrated on the characteristics of the users (Boogers and Voerman, 2003; Hooghe and Teepe, 2007; Marschall, 2005; Wall et al., 2009). ${ }^{5}$

With the growing number of voters using these tools during election times, the interest has arisen concerning the consistency, validity and reliability - to put it in a word, the quality - of the voting advice provided by such applications. This stream of VAA research has resulted in a number of articles dealing with the process of statement selection (Walgrave et al., 2009; Nuytemans et al., 2010), the way in which parties' positions on the statements are - or should be - established (Trechsel and Mair, 2011), the effect of different calculation methods on the final advice provided to users (Kleinnijenhuis and Krouwel, 2008; Louwerse and Rosema, 2011) and the impact of these tools on the logic of electoral competition (Ramonaite, 2010). 
This body of research on VAA methodology can be boiled down to one crucial finding: namely that the design of the tool matters. For example, Walgrave et al. (2009) show by means of experimental simulation that the respective composition of theses has an impact on the advice which is provided by a VAA. Changes in the selection of statements produce different outcomes in terms of the voting advice generated by the tool. Analogously, Louwerse and Rosema (2011) as well as Kleinnijenhuis and Krouwel (2008) find that by applying different methods of calculation the proximity between parties and users indicated by the VAA varies remarkably, even changing the rank order of the parties. Such research on VAA methodology raises awareness on how much responsibility is given to the developers of VAAs (and political scientist involved in the making-of), as their decisions for a specific design and methods could exert a heavy influence on the quality of the tool (Ladner et al. 2010) and on its possible effects on voters - the latter representing the most investigated aspect so far in the existing VAA literature.

At first, VAAs have been found to prompt users to collect further information about politics and political parties. A number of post-test surveys conducted among "Wahl-OMat" users in Germany show that between $50 \%$ and $60 \%$ of respondents declare to be motivated to collect further political information after having performed the VAA (Marschall, 2005; Marschall and Schmidt, 2010). Similar figures are reported in the case of "Vaalikone" users in Finland (Mykkänen et al., 2007) and "StemWijzer" users in The Netherlands (Boogers 2006). Lower figures come from Italy, where a post-test survey conducted in 2009 among "cabina-elettorale.it" users reports that one respondent in five has been motivated to collect further information after using the tool (De Rosa, 2010).

Recent studies on political internet communication suggest that the online environment has the potential to bring previously uninvolved citizens into politics and the political process (Norris, 2001, pp.84-86). Research on VAAs confirms these assumptions (for the case of young voters, see Hirzalla et al., 2011). Obviously, cognitive effects would be of little relevance if we could not detect any reflection in the actual behaviour of users. The search for more information "can serve to increase one's competences in understanding politics by affecting the extent and quality of individuals' political activities" (Marschall and Schmidt, 2010, p.82). Indeed, a growing body of research shows that VAAs can also affect vote choice, both quantitatively (turnout) and qualitatively (vote intention).

VAA providers have great confidence in the mobilising capacity of these tools (Ruusuvirta and Rosema, 2009), and some VAAs are actually developed as an attempt to mobilise voters and increase turnout (Marschall, 2005). Previous studies on the impact of political knowledge on turnout show that higher levels of political information correspond to a decreased likelihood of abstaining (Delli Carpini and Keeter, 1996). Research on the impact of VAA usage on turnout reinforces this conclusion. A study by Mykkänen and Moring (2007) found that after controlling for socio-demographic variables, using a VAA increased the likelihood of voting by roughly $20 \%$ in the 2003 Finnish parliamentary election. Lower figures are reported by Marschall and Schmidt (2010) for Germany (10\% of post-test survey respondents "considered voting" in the European elections of 2009 thanks to the test), by Boogers (2006) for the Netherlands (11\% "considering voting" in the parliamentary election of 2006), and by Ladner and Pianzola (2010) for Switzerland (15\% "definitely motivated to vote" in the 2007 Swiss federal election). When it comes to aggregate effects on turnout, Ruusuvirta and Rosema's (2009) analysis of the Dutch parliamentary election of 2006 concludes, as a 
best estimate, that "the usage of online vote selectors increased electoral turnout with 3\%" (Ruusuvirta and Rosema, 2009, p.18), whereas this figure goes up to 5\% for Switzerland (Fivaz and Nadig, 2010). VAAs have been found to exert an effect on individual propensity to turn out also in supranational, i.e., European elections. A study by Dinas et al. (2012) could show that even after controlling for a set of sociodemographic, attitudinal and behavioural variables, the probability to participate in European elections is about $14 \%$ higher for VAA users as compared to non-users.

Finally, VAAs have been found to affect the actual vote choice of users. A small but significant proportion of the tools' users do declare that they will switch their vote in accordance with the advice obtained. According to the available evidence, the proportion of self-declared swing-voters among VAA users appears quite varied across different national settings, ranging from $2-3 \%$ in Belgium (Nuytemans et al., 2010) and Italy (De Rosa, 2010) to about 6\% in Germany (Marschall, 2005) up to above 10\% in Finland (Mykkänen et al., 2007), Switzerland (Ladner et al., 2010; Ladner, 2012) as well as in The Netherlands (Boogers, 2006). A cross-national analysis of EU Profiler data found about $8 \%$ of users declaring to be willing to switch their top-party preference to become consistent with the party proposed by the application (Alvarez et al., 2012).

Recent analyses have focused on the conditions under which VAAs make individual voters alter their vote choice, identifying intervening variables in the individual propensities as well as in the specific interaction between users and the tool. On the one hand, Pianzola (2011) finds that the likelihood of changing the vote choice after using a VAA is directly related to the level of political knowledge of the users. On the other hand, Wall et al. (2012) show that whether and how a VAA affects the voting decision is strongly influenced by the degree of congruence between the recommended party on the one hand and the users' pre-existing party preferences on the other hand.

\section{Towards a research agenda}

\subsection{Political behaviour}

One of the crucial problems with the assessment of VAA effects on voting behaviour is related to the manner in which these are investigated. Most studies rely on data from post-test surveys administered randomly to VAA users. In modelling VAA effects based on these sources, however, it must be taken into account the self-selected, non-random nature of the samples at hand. The individuals of these samples have not only selfselected themselves to becoming VAA users: they have also deliberately chosen to take part in the post-test survey. As a result, chances are that "we might end up with a sample of highly enthusiastic and convinced [VAA] users who report stronger effects of the tool on their voting behaviour than if we had had the chance to survey a representative sample of [VAA] users" (Pianzola and Ladner, 2011, p.6). In this sense, accounting for the nonrandom event of individual participation in the post-test survey through advanced statistical techniques (e.g. Heckman models) would seem a fruitful way to go for future research of VAA effects when resorting to exit survey methods (Vassil, 2011).

With respect to individual-level effects, recent studies have demonstrated that the reported intention to change vote choice in accordance with the advice provided is not always matched with actual changes in voting behaviour. Findings in the Belgian case show that "among the small group of people saying that [VAA] really made them change 
their mind, one third did not change their mind at all and remained loyal" (Walgrave et al., 2008, pp.65-66; similar figures for the Dutch case are reported in Kleinnijenhuis and van Hoof, 2008). In order to overcome these limitations, a number of proposals have been advanced. Kleinnijenhuis and van Hoof (2008) call for a longitudinal research design, including: "a panel survey study to collect in successive points in time data about one's priori beliefs, about the actual advice obtained from a party profiling website and in the end about one's vote. Moreover, data regarding one's personal choice of newspapers and television news bulletins should be obtained" (Kleinnijenhuis and van Hoof, 2008, p.5).

Another serious problem for scholars dealing with VAA effects is the difficulty in isolating the specific impact of using these tools on voting behaviour. Any measurable change in vote choice might also be traced back to other intervening factors such as candidate orientation (Ruusuvirta and Rosema, 2009). A way to isolate specific VAA effects could be provided by pure (Vassil, 2012) or quasi-experimental designs. The latter strategy is employed by Alvarez et al. (2012) in their analysis of EU Profiler generated data. After using the tool, EU Profiler users were asked to state their propensity to vote (on a 0-to-10 scale) for each of the competing parties. After having provided the user with the name of the parties closest to him/her, the application asked once again to state the individual propensity to vote for each of the parties. Based on this research design, Alvarez and colleagues have been able to show the actual impact of the application by looking at the changing patterns (pre/post usage) of vote propensity - a more reliable, albeit indirect, measure of a VAA effect. Also Wall et al. (2012) worked with such a panel design; however, both studies draw on data generated by asking those who participated in the tool, thus facing the aforementioned problem of self-selection. This trade-off could be solved either by employing advanced statistical techniques to overcome self-selection biases (see above) or by working in the context of representative surveys (i.e. being a part of national election studies).

\subsection{Parties and elections}

Whereas the effects of VAAs on electoral behaviour have already been addressed by research (still leaving questions unanswered), the "party dimension" of this tool lies comparably idle. So far, research effort has been put into understanding the effects of the tool on users. However, there are good reasons to assume that VAAs exert influence on the parties, too. Parties and their positions on policy issues are at the centre of these tools and in several VAAs, parties are involved in the process of the production of the propositions or of defining their stances on them.

Especially those VAAs that ask party representatives to authorise propositions might under certain conditions instigate parties to start a process of opinion forming on certain policy issues (de Graaf, 2010). To what strategies do parties resort in order to tackle the problem (i) if they have not yet developed a clear position on the questions addressed, or (ii) if there are conflicts between party factions on a policy issue? The first case might predominantly apply for single-issue parties that do not offer a comprehensive policy programme. Being asked to position themselves on different topics within a VAA might either lead to "non-attitudes" (i.e. parties answering propositions rather randomly) or ideological inconsistencies (Ramonaite, 2010), but it might also result in opinion-forming processes within the respective party organisation. In case of an intra-party conflict on the issue, the party might omit the proposition or choose a middle category of the answer 
pattern. However, VAAs could contribute to clearing processes within the parties, stimulating party actors to overcome their conflicts. Little is known about these VAAinitiated processes within the parties. Research on such intraparty practices could provide an insight into the way parties develop their policy positions and whether the type of the party makes a difference in this respect.

Apart from effects on party organisation and intra-party decision making, VAA research could focus more on the issue side of the tool. As a result of the spread of VAAs, a multitude of parties within Europe have positioned themselves along a multitude of policy issues, producing a large dataset on policy positions of parties within Europe that could be used for party research. The positions parties take within Voting Advice Applications could be interrelated with the parties' platforms, thereby generally contributing to "manifesto" research (Budge et al., 2001; Klingemann et al., 2006). In those VAAs in which the parties themselves decide on their position on the policy issues, it might be instructive to compare the parties' stances on the concrete issues with their broader formulated party platforms, indicating inconsistencies or even conflicts between the parties' VAA answers on the one hand and the parties' general ideological positions on the other hand (for example see Wagner and Ruusuvirta, 2009).

Additionally, VAAs provide data on the question whether and how far parties translate their election pledges into decision-making once they have come into power, by comparing the results of political decision-making after the elections with the policy positions the parties took within the VAAs (Skop, 2010). These findings could be easily linked, again, to manifesto research. Any differences could expose effective constraints on policy-making (e.g. the formation of coalition governments or the multilevel constellation of policy-making).

The multitude of party positions produced by VAAs could also be used to mark out the issue room parties are located in (e.g. Costa Lobo et al., 2010; Gemenis, 2011; Talonen and Sulkava, 2011). By using statistical techniques like factor or cluster analysis it might be possible to identify new cleavage lines that structure the party room, overcoming or supporting the left-right dichotomy (for example see Kleinnijenhuis and Krouwel, 2009; Otjes and Lowerse, 2011). Especially in tools like the "EU Profiler" or the "EU-Votematch" these party positions have been surveyed all across Europe. Drawing on this data allows for an empirical identification of party families within the European Union, by calculating the likenesses of parties in different countries on several policy dimensions. Such a cluster analysis might point to alternative ways in grouping the parties in Europe which might not necessarily correspond to the already existing party family structure.

\subsection{Political communication}

As with the "party dimension" of these tools, the "media dimension" of Voting Advice Applications has also been substantially neglected by research so far. However, communication and media science could contribute to a better understanding of the web applications and in turn profit from the findings of VAA research.

First, VAAs produce identifiable media effects that are normally not easy to isolate (Bryant and Oliver, 2009). According to several studies on the tool and its users (Section 4), VAAs have the potential to influence whether and how people take advantage of their right to vote. This specific impact of the tool can only be understood by taking into consideration the intervening effects of the media system in which VAAs are located. 
Looking from the perspective of the recipients, VAAs belong to the media repertoire individuals have at their disposal in order to gather information about politics, parties and policies. On the individual level, interdependence between the usage of VAAs and other media can be assumed. How does the use of VAAs influence the importance of other channels of information, be it the traditional media, peer groups or newest media formats like the Web 2.0? Does the use of VAAs supplement the already existing media repertoire of recipients or does it substitute traditional resources (Küng et al., 2008)?

Second, VAAs themselves are objects of coverage by the traditional media. Whether newspapers, TV and radio report about the implementation of VAAs depends on their news values. Especially when the tool is used for the first time, when it produces surprising results, or when there is a conflict concerning the tool (e.g. a party retreats from participation), media coverage is probable (de Graaf, 2010). Additionally, an analysis of the coverage could address the media-constructed role of VAAs for elections, parties and voters: How are VAAs discussed in newspapers, radio and TV broadcasting? What frames are used in the coverage of Voting Advice Applications?

Third, in many cases, the application of the tool is accompanied by public relations strategies. By issuing press releases, by organising events like VAA launch parties, media coverage of the tool is supposed to be instigated. Are these PR efforts successful and if so, under which circumstances? Some VAAs have been from the beginning combined with other media formats. For example, the Belgian VAA "Doe de Stemtest!" was linked to a TV show (Walgrave et al., 2008). By focusing on the coverage of VAA usage by the traditional media and how this coverage has been initiated, cross-media phenomena as well as cross-media strategies can be analysed.

\subsection{Democratic theory}

So far, VAAs have chiefly been addressed from the perspective of empirical research. However, first initiatives have started to understand VAAs from the angle of political and democratic theory, too. As a matter of fact, the development and implementation of VAAs carry normative implications and reflect theoretical assumptions which deserve scrutiny and discussion. This can be illustrated by the idea of "citizenship" as entrenched in Voting Advice Applications and their assumed effects on voters. According to classic democratic theorists such as Mill, Locke, and Tocqueville, the prerequisite for a working representative democracy is that citizens/voters possess an acceptable level of political abilities in terms of knowledge, understanding of, and interest in political matters. However, with the rise of survey research in the last century, the stunning contrast between the traditional image of a "citoyen" and the real nature of contemporary voters has become evident (Berelson et al. 1954; Campbell et al., 1960). This could be the basis to understand the use of VAAs as a potential resource to leveraging individual voters' competences (Fossen and Anderson, 2011).

Ideally, VAAs would seem to allow citizens to raise their competence in order to fulfil the "requirement" of rational decision-making (Downs, 1957). However, taken from such a normative perspective, a number of fundamental questions must be raised: To what extent does VAA usage accord with reasonable expectations regarding citizen competence? What standards should VAAs meet in order to fulfil such normatively based expectations? Are there ways of (re)designing VAAs to better realise central values of transparency and accessibility? 
Only recently has the VAA research community started investigating such questions (Cedroni, 2010; Ladner et al., 2010; Skop, 2010; Fossen and Anderson, 2011). A theoretical perspective on VAAs can shed light onto the (contestable) normative presuppositions on which these tools are developed and, in turn, onto the underlying models of democracy and citizenship which are embedded in the different modes in which VAAs are implemented. In this sense, future research might focus on the conditions under which different VAAs contribute to diverse models of democracy (Cedroni, 2010). Anyway, normative questions will become increasingly relevant with the progressive growth of users resorting to VAAs during election times.

From the point of view of empirical democratic theory, VAA research has begun to link the potentials of VAAs with the concept of a "representative deficit" (Dinas et al., 2011; Alvarez et al., 2012). To the extent that representative democracy is about the match between the partisan offer and the voters' issue preferences, VAAs can represent a fruitful means to assess the degree of congruence between parties and voters. In turn, this can help to answer fundamental questions related to electoral disenfranchisement at the individual level as indicated by declining turnout rates.

\section{Conclusions}

Voting Advice Applications are online-based tools that compare positions of candidates/parties with positions of the voters, indicating which party is the closest to the individual voter on the basis of selected issues. VAAs have spread throughout Europe within the last years and have been applied in the vast majority of European countries. Social science research has begun to address the role and the effects of these tools and to especially consider their impact on voting behaviour. However, there are still many questions unanswered as well as alternative perspectives on VAAs to be explored (for instance focusing on their implications for party organisations and political communication).

Due to their nature of being online tools that focus on policy issues and positions of parties and candidates, VAAs might play an even more decisive role in the future. As modern democracies turn out to be more heterogeneous and individualised, processes of dealignment will continue as will the decline of party identification and cleavage voting. Issue voting will most likely become more relevant in the future. VAAs fit this tendency, as they offer a "cheap" cue for the by all accounts increasing number of voters who base their voting decision on a comparison between the parties' policy offers and their own policy preferences.

The web itself has turned into a salient source of political information and participation - for many recipients even surpassing the traditional media. Especially young voters tend to rely on the internet in order to find information and orientation for their voting decision. In all probability, web-based information tools such as VAAs will become more important, especially if they can be embedded in Web 2.0 structures.

These developments call for a common endeavour to connect as yet isolated attempts to work on the tool, promoting a comparative perspective. As outlined above, there are large divergences between the findings presented in the existing VAA literature. For this reason, much more attention to international comparisons is needed. In order to develop analyses based on comparable empirical measures, a first step could be that of 
developing common questionnaires (Fivaz et al., 2010) to be implemented in VAA posttest surveys and, optimally, in national election studies (as is already the case in Finland and The Netherlands).

A promising trend lies in the increasingly widespread development of supranational VAAs, such as "EU-Votematch" and the "EU Profiler". The latter project seems particularly fruitful inasmuch it has been originally conceived in close coordination with one of the most established research programmes on electoral behaviour - the European Election Study (Breuer, 2010). This collaboration represents a step forward in linking CATI interview technology with an innovative, alternative method of online data gathering (Franklin and Trechsel, 2008) and demonstrates the huge potential of VAAs specifically to enhance our understanding of the reasoning underlying voters' choices. In turn, findings from VAA research might effectively contribute to more general debates on voting behaviour, political communication, party formation and organisation.

\section{References}

Aardal, B. and van Wijnen, P. (2005) 'Issue voting', in Thomassen, J. (Ed.): The European Voter, Oxford University Press, Oxford, pp.192-212.

Alvarez, R.M., Levin, I., Mair, P. and Trechsel, A.H. (2012) 'Party Preferences in the Digital Age: The Impact of Voting Advice Applications', Paper prepared for the conference Responsive or Responsible? Parties, Democracy and Global Markets. A conference in honour of Peter Mair, Florence, 26-28 September.

Berelson, B.R., Lazarsfeld, P.F. and McPhee, W.N. (1954) Voting. A Study of Opinion Formation in a Presidential Campaign, University of Chicago Press, Chicago.

Boogers, M. (2006) Enquete bezoekers Stemwijzer, unpublished paper, Universiteit van Tilburg, Tilburg.

Boogers, M. and Voerman, G. (2003) 'Surfing citizens and floating voters: results of an online survey of visitors to political web sites during the Dutch 2002 General Elections', Information Polity, Vol. 8, Nos. 1/2, pp.17-27.

Breuer, F. (2010) 'The EU profiler: a new way for voters to meet parties and to understand European elections', in Gagatek, W. (Ed.): The 2009 Elections to the European ParliamentCountry Reports, European Union Democracy Observatory, Florence, pp.27-31.

Bryant, J. and Oliver, M.B. (Eds) (2009) Media Effects: Advances in Theory and Research, Routledge, New York.

Budge, I., Klingemann, H.D., Volkens, A., Bara, J. and Tanenbaum, E. (2001) Mapping Policy Preferences: Estimates for Parties, Electors, and Governments 1945-1998, Oxford University Press, Oxford.

Campbell, A., Converse, P.E., Miller, W.E. and Stokes, D.E. (1960) The American Voter, The University of Chicago Press, Chicago and London.

Carmines, E.G. and Huckfeldt, R. (1996) 'Political behavior: an overview', in Goodin, R.E. and Klingemann, H.D. (Eds): A New Handbook of Political Science, Oxford University Press, New York, pp.223-254.

Cedroni, L. (2010) 'Voting advice applications in Europe: a comparison', in Cedroni, L. and Garzia, D. (Eds): Voting Advice Applications in Europe. The State of the Art, ScriptaWeb, Napoli, pp.247-257.

Cedroni, L. and Garzia, D. (2010) Voting Advice Applications in Europe: The State of the Art, Scriptaweb, Napoli.

Chadwick, A.J. and Howard, P.N. (Eds) (2009) Routledge Handbook of Internet Politics, Routledge, London. 
Costa Lobo, M., Vink, M. and Lisi, M. (2010) 'Mapping the political landscape: a vote advice application in Portugal', in Cedroni, L. and Garzia, D. (Eds): Voting Advice Applications in Europe. The State of the Art, ScriptaWeb, Napoli, pp.143-185.

Dalton, R.J. (2002) 'Political cleavages, issues, and electoral change', in LeDuc, L., Niemi, R. and Norris, P. (Eds): Comparing Democracies 2, Sage, London, pp.189-209.

Dalton, R.J. and Wattenberg, M.P. (2000) Parties without Partisans: Political Change in Advanced Industrial Democracies, Oxford University Press, Oxford.

Dalton, R.J., McAllister, I. and Wattenberg, M.P. (2000) 'The consequencies of partisan dealignment', in Dalton, R.J. and Wattenberg, M.P. (Eds): Parties without Partisans. Political Change in Advanced Industrial Democracies, Oxford University Press, Oxford, pp.37-63.

De Rosa, R. (2010) 'cabina-elettorale.it (Provides advice to Italian voters since 2009)', in Cedroni, L. and Garzia, D. (Eds): Voting Advice Applications in Europe. The State of the Art, ScriptaWeb, Napoli, pp.187-212.

Delli Carpini, M.X. and Keeter, S. (1996) What Americans Know about Politics and Why It Matters, Yale University Press, New Haven and London.

Dinas, E., Trechsel, A.H. and Vassil, K. (2011) 'A look into the mirror. Preferences, representation and electoral participation', Paper presented at the Conference Internet, Voting and Democracy, 12-13 May 2011, Laguna Beach, USA.

Downs, A. (1957) 'An economic theory of political action in a democracy', The Journal of Political Economy, Vol. 65, No. 2, pp.135-150.

Edwards, A.R. (1998) 'Towards an informed citizenry? Information and communication technologies and electoral choice', in Snellenm, I.Th.M. and van de Donk, W. (Eds): Public Administration in an Information Age. A Handbook, IOS Press, Amsterdam, pp.191-206.

Farrell, D. and Schmitt-Beck, R. (Eds) (2008) Non-Party Actors in Electoral Politics: The Role of Interest Groups and Independent Citizens in Contemporary Election Campaigns, Nomos, Baden-Baden.

Fivaz, J. and Nadig, G. (2010) 'Impact of Voting Advice Applications (VAAs) on voter turnout and their potential use for civic education', Policy \& Internet, Vol. 2, No. 4, pp.167-200.

Fivaz, J., Pianzola, J. and Ladner, A. (2010) 'More than toys: a first assessment of voting advice applications' impact on the electoral decision of voters', National Centre of Competence in Research (NCCR): Challenges to Democracy in the 21st Century, Working Paper No. 48.

Fossen, T. and Anderson, J. (2011) 'Conflicting conceptions of what voting advice applications are supposed to accomplish', Paper presented at the 10th Politicologenetmaal, 9-10 June 2011, Amsterdam, The Netherlands.

Franklin, M.N. and Trechsel, A.H. (2008) 'Matching voting advice applications and traditional surveys in electoral studies: the EES and EU profiler', Paper presented at The Conference Voting Advice Applications (VAAs): Between Charlatanism and Political Science, 16 May 2008, Antwerp, Belgium.

Franklin, M.N., Mackie, T.T. and Valen, H. (1992) Electoral Change: Responses to Evolving Social and Attitudinal Structures in Western Societies, Cambridge University Press, Cambridge.

Garzia, D. (2010) 'The effects of VAAs on users' voting behaviour: an overview', in Cedroni, L. and Garzia, D. (Eds): Voting Advice Applications in Europe. The State of the Art, ScriptaWeb, Napoli, pp.13-33.

Gemenis, K. (2011) 'Estimating the positions of political actors through voting advice applications: some methodological considerations', Paper presented at the Dutch and Flemish Political Science Associations Annual Meeting (Etmaal), 9-10 June, Amsterdam, The Netherlands.

Gibson, R., Nixon, P. and Ward, S. (Eds) (2003) Political Parties and the Internet: Net Gain?, Routledge, New York.

de Graaf, J. (2010) 'The irresistible rise of Stemwijzer', in Cedroni, L. and Garzia, D. (Eds): Voting Advice Applications in Europe. The State of the Art, ScriptaWeb, Napoli, pp.35-60. 
de Graaf, J. and Schuszler, P. (2005) The Rise of Stemwijzer, Unpublished manuscript.

Hirzalla, F., van Zoonen, L. and de Ridder, J. (2011) 'Internet use and political participation: reflections on the mobilization/normalization controversy', The Information Society, Vol. 27, pp.1-15.

Hooghe, M. and Teepe, W. (2007) 'Party profiles on the web: an analysis of the logfiles of nonpartisan interactive political internet sites in the 2003 and 2004 election campaigns in Belgium', New Media Society, Vol. 9, No. 6, pp.965-985.

Kies, R. and Dumont, P. (2011) 'Smartvote in Luxembourg: usage and impact of a new electoral tool', Paper presented at the European Consortium for Political Research (ECPR) General Conference, 24-27 August 2011, Reykjavik, Iceland.

Kleinnijenhuis, J. and Krouwel, A. (2008) Simulation of Decision Rules for Party Advice, Unpublished paper, Amsterdam.

Kleinnijenhuis, J. and Krouwel, A. (2009) 'Dimensionality of the European issue space', Paper presented at the NCCR Bern Workshop Vote Advice Applications, 12-13 November 2009, Bern, Switzerland.

Kleinnijenhuis, J. and van Hoof, A. (2008) 'The influence of internet consultants', Paper presented at the Annual Meeting of the International Communication Association, 21 May 2008, Montreal, Canada.

Klingemann, H.D., Volkens, A., Budge, I., Bara, J. and McDonald, M.D. (2006) Mapping Policy Preferences II: Parties, Electorates and Governments in Eastern Europe and the OECD 1990-2003, Oxford University Press, Oxford.

Kluver, R., Jankowski, N., Foot, K.A. and Schneider, S.M. (2007) The Internet and National Elections: A Comparative Study of Web Campaigning, Routledge, New York.

Küng, L., Picard, R.G. and Towse, R. (Eds) (2008) The Internet and the Mass Media, Sage, London.

Ladner, A. (2012) 'Voting advice applications - impact on voting decisions in the 2011 Swiss national elections', Paper presented at the 62nd Political Studies Association Annual International Conference, 3-5 April 2012, Belfast, Ireland.

Ladner, A. and Pianzola, J. (2010) 'Do voting advice applications have an effect on electoral participation and voter turnout? Evidence from the 2007 Swiss Federal Elections', in Tambouris, E., Macintosh, A. and Glassey, O. (Eds): Electronic Participation. 2nd IFIP WG 8.5 International Conference, ePart 2010, Lausanne, Switzerland, 29 August-2 September 2010, Springer, Berlin, pp.211-224.

Ladner, A., Felder, G. and Fivaz, J. (2010) 'More than toys? A first assessment of voting advice applications in Switzerland', in Cedroni, L. and Garzia, D. (Eds): Voting Advice Applications in Europe. The State of the Art, ScriptaWeb, Napoli, pp.91-123.

Leighley, J.E. (2010) The Oxford Handbook of American Elections and Political Behavior, Oxford University Press, Oxford.

Lowerse, T. and Rosema, M. (2011) 'The design effects of voting advice applications: comparing methods of calculating results', Paper presented at the European Consortium for Political Research (ECPR) General Conference, 24-27 August, Reykjavik, Iceland.

Marschall, S. (2005) 'Idee und Wirkung des Wahl-O-Mat', Aus Politik und Zeitgeschichte, Vol. 55, Nos. 51/52, pp.41-46.

Marschall, S. and Schmidt, C.K. (2010) 'The impact of voting indicators: the case of the German Wahl-O-Mat', in Cedroni, L. and Garzia, D. (Eds): Voting Advice Applications in Europe. The State of the Art, ScriptaWeb, Napoli, pp.65-104.

Marzuca, A., Serdült, U. and Welp, Y. (2011) 'Questão Pública: first voting advice application in Latin America', in Tambouris, E., Macintosh, A. and de Bruijn, H. (Eds): Electronic Participation, 3rd IFIP WG 8.5 International Conference, ePart 2011, Delft, The Netherlands, 29 August-1 September 2011, pp.216-227.

Mykkänen, J. and Moring, T. (2007) Dealigned politics comes of age? The effects of online candidate selectors on Finnish voters, unpublished manuscript, Helsinki. 
Mykkänen, J., Moring, T. and Pehkonen, J. (2007) Tutkimus vaalikoneiden käytöstä ja suhtautumisesta vaalikoneisiin: Vaalikoneet koetaan hyödyllisiksi, Helsingin Sanomain säätiö, Helsinki.

Norris, P. (2001) Digital Divide. Civic engagement, information poverty, and the Internet Worldwide, Cambridge University Press, Cambridge.

Norris, P. (2008) 'Getting the message out: a two-step model of the role of the internet in campaign communication flows during the 2005 British General Election', Journal of Information Technology \& Politics, Vol. 4, pp.3-13.

Nuytemans, M., Walgrave, S. and Deschouwer, K. (2010) 'Do the vote test: the Belgian voting aid application', in Cedroni, L. and Garzia, D. (Eds): Voting Advice Applications in Europe. The State of the Art, ScriptaWeb, Napoli, pp.125-156.

Otjes, S. and Louwerse, T. (2011) 'Spatial models in Voting Advice Applications', Paper presented at The 10th Politicologenetmaal, 9-10 June 2011, Amsterdam, The Netherlands.

Pianzola, J. (2011) 'The interplay between political knowledge and VAA use and its effect on voting behavior', Paper presented at the 10th Politicologenetmaal 2011, 9-10 June 2011, Amsterdam, The Netherlands.

Pianzola, J. and Ladner, A. (2011) 'Tackling self-selection into treatment and self-selection into the sample biases in VAA research', Paper presented at the European Consortium for Political Research (ECPR) General Conference, 24-27 August 2011, Reykjavik, Iceland.

Ramonaite, A. (2010) 'Voting advice applications in Lithuania: promoting programmatic competition or breeding populism?', Policy \& Internet, Vol. 2, No. 1, pp.117-147.

Ruusuvirta, O. (2010) 'Much ado about nothing? Online voting advice applications in Finland', in Cedroni, L. and Garzia, D. (Eds): Voting Advice Applications in Europe. The State of the Art, ScriptaWeb, Napoli, pp.47-77.

Ruusuvirta, O. and Rosema, M. (2009) 'Do online vote selectors influence electoral participation and the direction of vote?', Paper presented at The European Consortium for Political Research (ECPR) General Conference, 10-12 September 2009, Potsdam, Germany.

Scarrow, S.E. (2010) 'Political parties and party systems', in LeDuc, L., Niemi, R.G. and Norris, P. (Eds): Comparing Democracies 3. Elections and Voting in the 21st Century, Sage Publications, London, Thousand Oaks, New Delhi and Singapore.

Skop, M. (2010) 'Are the Voting Advice Applications (VAAs) telling the truth? Measuring VAAs' quality: case study from the Czech Republic', in Cedroni, L. and Garzia, D. (Eds): Voting Advice Applications in Europe. The State of the Art, ScriptaWeb, Napoli, pp.199-230.

Talonen, J. and Sulkava, M. (2011) 'Analyzing parliamentary elections based on voting advice application data', IDA'11 Proceedings of the 10th International Conference on Advances in Intelligent Data Analysis, pp.340-351.

Trechsel, A.H. and Mair, P. (2011) 'When parties (also) position themselves: an introduction to the EU profiler', Journal of Information Technology \& Politics, Vol. 8, No. 1, pp.1-20.

Vassil, K. (2011) 'Role of self selection in estimating the effects of voting advice applications: empirical evidence on the basis of Swiss smartvote data', Paper presented at the European Consortium for Political Research (ECPR) General Conference, 24-27 August 2011, Reykjavik, Iceland.

Vassil, K. (2012) Voting smarter? The Impact of Voting Advice Applications on Political Behavior, Unpublished doctoral dissertation. European University Institute, Florence.

Wagner, K.M. and Gainous, J. (2009) 'Electronic grassroots: does online campaigning work?', Journal of Legislative Studies, Vol. 15, No. 4, pp.502-520.

Wagner, M. and Ruusuvirta, O. (2009) 'Faulty recommendations? Party positions in online voting advice applications', Paper presented at The APSA 2009, 3-6 September 2009, Toronto, Canada.

Wagner, M. and Ruusuvirta, O. (2011) 'Matching voters to parties: voting advice applications and models of party choice', Acta Politica, Vol. 47, No. 4, pp.400-422. 
Walgrave, S., Nuytemans, M. and Pepermans, K. (2009) 'Voting aid applications and the effect of statement selection', West European Politics, Vol. 32, No. 6, pp.1161-1180.

Walgrave, S., van Aelsta, P. and Nuytemans, M. (2008) "Do the Vote Test": the electoral effects of a popular vote advice application at the 2004 Belgian elections', Acta Politica, Vol. 43, No. 1, pp.50-70.

Wall, M., Krouwel, A. and Vitiello, T. (2012) 'Do voters follow the recommendations of voter advice application websites? A study of the effects of Kieskompas.nl on its users' vote choices in the 2010 Dutch legislative elections', Party Politics, doi: 10.1177/1354068811436054.

Wall, M., Sudulich, M.L., Costello, R. and Leon, E. (2009) 'Picking your party online: an investigation of Ireland's first online voting advice application', Information Polity, Vol. 14, No. 3, pp.203-218.

Zittel, T. and Fuchs, D. (Eds) (2007) Participatory Democracy and Political Participation: Can Participatory Engineering Bring Citizens Back In?, Routledge, New York.

\section{Notes}

1 These applications have been labelled differently: Voting Indicators (Boogers and Voerman, 2003), Party Profile Websites (Hooghe and Teepe, 2007), Political Internet Consultants (Kleinnijenhius and van Hoof, 2008), Online Vote Selectors (Ruusuvirta and Rosema, 2009) just to mention some examples from the most recent literature. In this article we will refer to them as Voting Advice Applications because of the seemingly emerging consensus on such a denomination - or, at least, on the "VAA" acronym (Walgrave et al., 2008; Cedroni and Garzia, 2010; Nuytemans et al., 2010).

2 It should be clarified that the amount of advices provided by the application does not necessarily correspond to the number of users that the VAA has been able to attract. Indeed, Kies and Dumont (2011) show that, on average, VAA users perform the test more than twice. Accordingly, they propose the number of user sessions (based on the IP address) as a rather more reliable measure of VAA usage. However, this measure was not available with respect to all the VAAs featured in our survey. We therefore resorted to the amount of advices provided for the sake of cross-national comparability.

3 If the voter agrees with a thesis $(+)$ and the party disagrees $(-)$, the difference is maximum ( 2 points). If a voter has the same opinion as the party (agree, disagree or neutral), then there is no difference ( 0 points). If a voter or a party takes a neutral standpoint, the score is 1 ; if both the voter and the party take the neutral standpoint, then the score is 0 .

4 Further information about NECE and its activities can be found at http://www.bpb.de/ veranstaltungen/PAJZMN.

5 According to these studies, the typical VAA user is male, young, well-educated, and highly interested in politics. 